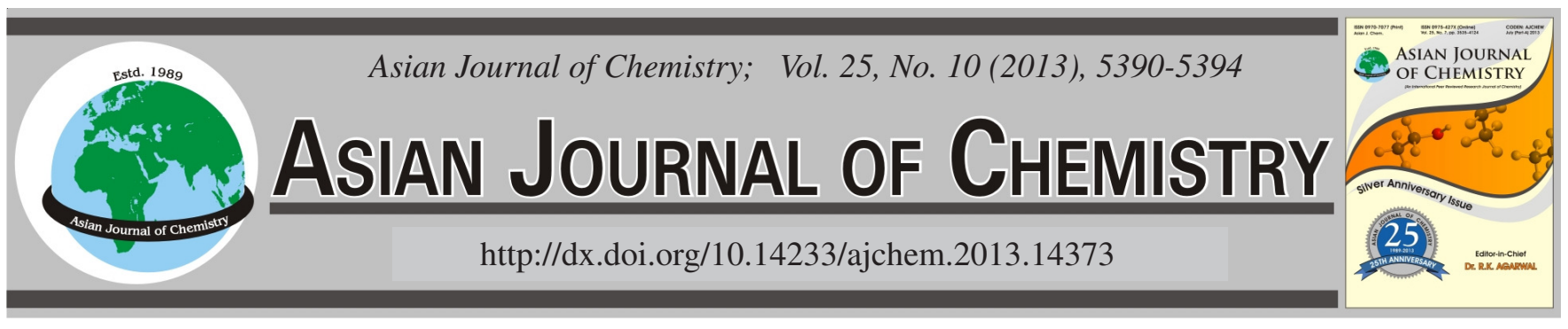

\title{
Preparation of Expandable Graphite with Phosphoric Acid as Ancillary Intercalation Reagent and its Antiflame Property for Linear Low Density Polyethylene
}

\author{
Xiu-Yan Pang ${ }^{*}$, Ming-Wei Duan, Yu Tian and Meng Zhai
}

College of Chemistry and Environmental Science, Hebei University, Baoding 071002, P.R. China

*Corresponding author: E-mail: pxy833@163.com

To prepare graphite intercalation compound-expandable graphite (EG) with well antiflame property for linear low density polyethylene (LLDPE), dosages of oxidant $\mathrm{KMnO}_{4}$, intercalation reagent $\mathrm{H}_{2} \mathrm{SO}_{4}$ and ancillary intercalation reagent $\mathrm{H}_{3} \mathrm{PO}_{4}$ were optimized during chemical oxidation intercalation reaction of natural graphite. Expandable graphite with an initiation expansion temperature of $160{ }^{\circ} \mathrm{C}$ and expansion volume of $430 \mathrm{~mL} / \mathrm{g}$ can be prepared according to the mass ratio $\mathrm{C}: \mathrm{KMnO}_{4}: \mathrm{H}_{2} \mathrm{SO}_{4}(98 \%): \mathrm{H}_{3} \mathrm{PO}_{4}(85 \%)$ of 1.0:0.2:3.0:0.3 $\left(\mathrm{H}_{2} \mathrm{SO}_{4}\right.$ should be diluted to the mass concentration of $75 \%$ before intercalation reaction), the reaction lasts $1 \mathrm{~h}$ at $40{ }^{\circ} \mathrm{C}$. Addition of $30 \%$ of the prepared expandable graphite to linear low density polyethylene can improve its limiting oxygen index (LOI) from $17.3 \%$ to 25.7 $\%$ and the synergistic anti-flame limiting oxygen index of $20 \%$ expandable graphite with $10 \%$ ammonium polyphosphate (II) (APP II) can reach to $27 \%$. Thermal gravimetric and differential thermal analysis were completed to discuss the antiflame mechanism. $70 \%$ LLDPE/10 \% APP(II)/20 \% EG synergistic antiflame system can cause higher residual carbon and lower material surface temperature.

Key Words: Expandable graphite, Linear low density polyethylene, Flame retardancy, Dilatability, Phosphoric acid, Residual carbon.

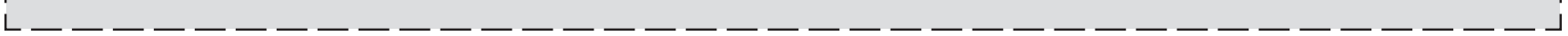

\section{INTRODUCTION}

To improve the antiflame capability of polyethylene (PE), addition of flame retardant (FR) additives are often needed, among which halogenated compounds are the most widely used and brominated additives are the main fire retardants $(\mathrm{FR})^{1}$. But during the combustion of flame retarding polymer based on these retardants, halogen acids are evolved ${ }^{2}$, people would be exposed to these irritants and potential corrosion damage to equipment would occur ${ }^{3}$. So much work has been done on halogen-free fire retardants. Intumescent additives ${ }^{4}$ provide a effectively way to impact burning performance of polymeric materials. Once exposed to a heat source ${ }^{5}$, intumescent systems develop a voluminous, stable carbonaceous layer on the surface of the material. This layer limits heat and mass transfer, as well as oxygen diffusion, between the heat source and the polymer thus interrupting the self-sustained combustion of the polymer.

Expandable graphite is prepared when non-carbonaceous reactants are inserted into the layers of graphite through chemical oxidation intercalation ${ }^{6,7}$ or electrochemical oxidation intercalation $^{8,9}$. When expandable graphite is heated, it will become expanded graphite with porous structure and high expanded volume ${ }^{10}$. So expandable graphite is a good intumescent type flame-retardant for its good capability of halogen- free, non-dropping, low-smoke and low pollution potential ${ }^{11,12}$. When expandable graphite exposes to flame, it can give a swollen multicellular char, which may protect materials from the heat of combustion, limit the access of oxygen to the polymer and reduce the production of smoke. Simultaneously, expandable graphite absorbs huge heat during the instant expansion, which can decrease the burning temperature. When it gets oxidized on reaction with $\mathrm{H}_{2} \mathrm{SO}_{4}$ at high temperature as showed in eqn. 1 , the releasing gases can reduce concentration of oxygen.

$$
\mathrm{C}+2 \mathrm{H}_{2} \mathrm{SO}_{4} \rightarrow \mathrm{CO}_{2} \uparrow+2 \mathrm{H}_{2} \mathrm{O} \uparrow+2 \mathrm{SO}_{2} \uparrow
$$

Both initiation expansion temperature and expansion volume (EV) are two important characteristics of expandable graphite $^{13}$. If its initiation expansion temperature is lower than materials' machining temperature, it will decompose during material machining, then cause void flame retardancy. While, too high initiation expansion temperature will cause expandable graphite doesn't work in the flaming early stage. In preparation of expandable graphite, its initiation expansion temperature and expansion volume are affected by oxidant, intercalation reagent, ancillary intercalation reagent, reaction time and reaction temperature. Wang et al. ${ }^{14}$ prepared an expandable graphite with an initiation expansion temperature of $130{ }^{\circ} \mathrm{C}$ and expansion volume of $350 \mathrm{~mL} / \mathrm{g}$ through $\mathrm{HNO}_{3} / \mathrm{HBrO}_{3} /$ 
$\mathrm{KMnO}_{4}$ intercalation system. With $85 \% \mathrm{H}_{2} \mathrm{SO}_{4}$ as inserting reagent and $\mathrm{KMnO}_{4}$ as oxidant, through oxidation and insertion, Pang et $a l .{ }^{15}$ prepared an expandable graphite with an initial temperature of $300{ }^{\circ} \mathrm{C}$ and expanded volume of $360 \mathrm{~mL} / \mathrm{g}$ according to the mass ratio $\mathrm{C}: \mathrm{KMnO}_{4}: \mathrm{H}_{2} \mathrm{SO}_{4}$ of 1.0:0.15:4.0 (diluted to the mass concentration of $50 \%$ ) and reaction $0.5 \mathrm{~h}$ at $45{ }^{\circ} \mathrm{C}$. Addition of $30 \%$ of this expandable graphite to ethylene vinyl acetate (EVA) can improve oxygen index from $20 \%$ to $28.1 \%$.

Phosphorus flame retardant ${ }^{16-18}$ is important flame retardants with good flame retardancy for its accelerating formation of charing layer and releasing PO', which can catch free radical such as $\mathrm{H} \cdot \mathrm{HO}$ and then stop combustion. In this research, $\mathrm{H}_{3} \mathrm{PO}_{4}$ with a mass concentration of $85 \%$ is used as phosphoruscontaining ancillary intercalation reagent in the intercalation reaction of graphite, through optimizing the dosage of oxidant $\mathrm{KMnO}_{4}$, intercalating reagent $\mathrm{H}_{2} \mathrm{SO}_{4}$, ancillary intercalation reagent $\mathrm{H}_{3} \mathrm{PO}_{4}$, reaction time and reaction temperature, to provide a suitable expandable graphite flame retardant for linear low-density polyethylene LLDPE possessing low machining temperature (less than $140{ }^{\circ} \mathrm{C}$ ) and burning temperature.

\section{EXPERIMENTAL}

SX3-4-13 Muffle furnace (Tientsin,precision of temperature \pm 0.1-0.4\% ${ }^{\circ} \mathrm{C}$ ), 101-3 Oven (Shanghai,precision of temperature $\pm 2^{\circ} \mathrm{C}$ ), Muller (Jiangsu), Y-4Q X-ray diffractometer (Dandong), JF-3 Limiting oxygen index LOI instrument (Chengde), DT-40 Thermal analysis instrument (Shimadzu) are used in this experiment.

Natural Graphite (C, 5092) is provided by Action Carbon CO. Ltd., Baoding. Acetic acid, $\mathrm{H}_{2} \mathrm{SO}_{4}\left(96-98 \%\right.$ ), $\mathrm{KMnO}_{4}$, ammonium polyphosphate gls-APP(II) are all analytical reagents. LLDPE 7540 is purchased from Daqing.

Preparation of expandable graphite: First, the reactants are quantified according to a definite mass ratio $\mathrm{C}: \mathrm{KMnO}_{4}$ : $\mathrm{H}_{2} \mathrm{SO}_{4}(98 \%): \mathrm{H}_{3} \mathrm{PO}_{4}(85 \%)$, and $\mathrm{H}_{2} \mathrm{SO}_{4}$ need to dilute to the required mass concentration. Then, under a constant temperature controlled with water bath, the quantified natural graphite is mixed with $\mathrm{H}_{2} \mathrm{SO}_{4}, \mathrm{KMnO}_{4}$ and $\mathrm{H}_{3} \mathrm{PO}_{4}$ in a $250 \mathrm{~mL}$ beaker, reaction lasts the required time. After reaction, the mixture is washed with de-ionized water and dipping $2 \mathrm{~h}$ until $\mathrm{pH}$ of waste-water reaches to 6.0-7.0, then filtrated and dried at 50$60{ }^{\circ} \mathrm{C}$ for $c a .6 \mathrm{~h}$, expandable graphite products are gained.

\section{Characterization of expandable graphite}

Initiation expansion temperature and expansion volume (EV): $0.3 \mathrm{~g}$ of the prepared expandable graphite is used to detect initiation expansion temperature and expansion volume ${ }^{15}$. Temperature corresponding to 1.5 times of expandable graphite initiation volume is defined as initiation expansion temperature and expanded volume is defined as the volume of expanded graphite corresponding to $1.0 \mathrm{~g}$ of expandable graphite, written as $\mathrm{mL} / \mathrm{g}$.

X-Ray diffraction: The X-ray diffraction spectra were recorded with an Y-4Q X-ray spectrometer using the $\mathrm{Cu} \mathrm{K}_{\alpha 1,2}$ radiation in the range $5^{\circ}<2 \theta<70^{\circ}$.

Measurement of expandable graphite flame retardancy: As flame retardant, a definite quantity of expandable graphite is added into LLDPE. After mix, extrusion, press and chop into sliver at $140^{\circ} \mathrm{C}$ and $10 \mathrm{MPa}$, the slivers are used to measure antiflame properties. LOI is detected according to Standard of GB/T2406-1993 with oxygen index instrument.

Thermal gravimetric analysis: Under $\mathrm{N}_{2}$ ambience with a flux of $25 \mathrm{~mL} / \mathrm{min}, 10 \mathrm{mg}$ of the detected sample is laid in porcelain crucible and then it is heated to $800{ }^{\circ} \mathrm{C}$ at a heating rate of $10^{\circ} \mathrm{C} / \mathrm{min}$. Changes of sample weight with temperature are recorded.

Differential thermal analysis: DTA is carried under atmosphere ambience with a flux of $60 \mathrm{~mL} / \mathrm{min} . \mathrm{Al}_{2} \mathrm{O}_{3}$ is used as reference compound and heating rate of $5,10,15,20^{\circ} \mathrm{C} /$ min are used.

\section{RESULTS AND DISCUSSION}

According to the previous researches ${ }^{15,19}$, influence of mass ratio of graphite to $\mathrm{KMnO}_{4}, \mathrm{H}_{3} \mathrm{PO}_{4}, \mathrm{H}_{2} \mathrm{SO}_{4}$ and its concentration, reaction time and reaction temperature on expandable graphite characteristics of initiation expansion temperature and expansion volume are tested and discussed.

Influence of $\mathrm{KMnO}_{4}$ dosage on expandable graphite expansion performance: In the range of $0.2-0.6 \mathrm{~g} / \mathrm{g}$, the influence of $\mathrm{KMnO}_{4}$ dosage is detected at the mass ratio $\mathrm{C}: \mathrm{H}_{2} \mathrm{SO}_{4}$ (98\%): $\mathrm{H}_{3} \mathrm{PO}_{4}(85 \%)$ of 1.0:3.0:0.3 (g/g) at $40{ }^{\circ} \mathrm{C}$ reacting for $1 \mathrm{~h}$ and $\mathrm{H}_{2} \mathrm{SO}_{4}$ is diluted to the mass concentration of $75 \%$ before reaction. Results showed in Fig. 1 illustrate that when the mass ratio of $\mathrm{KMnO}_{4}$ to $\mathrm{C}$ is controlled as $0.4: 1.0$, expandable graphite product possessing a top expansion volume of $470 \mathrm{~mL} / \mathrm{g}$. But the initiation expansion temperature of $140^{\circ} \mathrm{C}$ is too lower to fit for LLDPE. Insufficiency $\mathrm{KMnO}_{4}$ would cause an incomplete oxygenation of graphite and decrease of expansion volume; superfluous $\mathrm{KMnO}_{4}$ would cause excessive oxygenation of graphite and decrease of expandable graphite granularity and expansion volume. When it is set as $0.2 \mathrm{~g} / \mathrm{g}$, an initial expansion temperature and expansion volume of 160 ${ }^{\circ} \mathrm{C}, 416 \mathrm{~mL} / \mathrm{g}$ is obtained, which is fit for the machining and antiflame characteriztics of LLDPE.

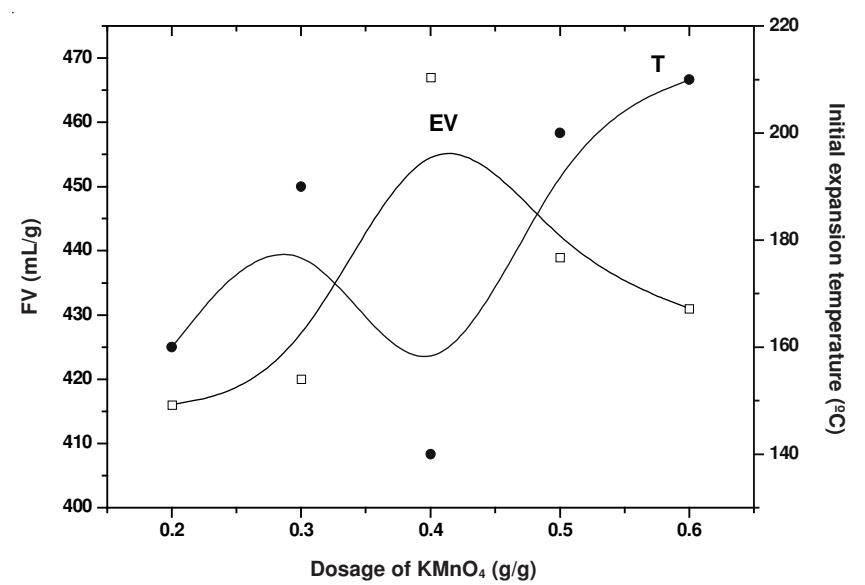

Fig. 1. Influence of $\mathrm{KMnO}_{4}$ dosage on initiation expansion temperature and expansion volume

Influence of $\mathrm{H}_{2} \mathrm{SO}_{4}$ dosage on expandable graphite expansion performance: In the range of $2.0-4.5 \mathrm{~g} / \mathrm{g}$, the influence of $\mathrm{H}_{2} \mathrm{SO}_{4}$ dosage with a mass concentration of $98 \%$ is detected at the mass ratio $\mathrm{C}: \mathrm{KMnO}_{4}: \mathrm{H}_{3} \mathrm{PO}_{4}(85 \%)$ of 1.0:0.2:0.3 $(\mathrm{g} / \mathrm{g})$ at $40{ }^{\circ} \mathrm{C}$ reacting for $1.0 \mathrm{~h}$ and $\mathrm{H}_{2} \mathrm{SO}_{4}$ is diluted 
to the mass concentration of $75 \%$ before reaction. Results showed in Fig. 2 illustrate that when the mass ratio of $\mathrm{H}_{2} \mathrm{SO}_{4}$ to $\mathrm{C}$ is controlled as 3.0:1.0, we can get expandable graphite with bottom initiation expansion temperature of $164^{\circ} \mathrm{C}$ and top expansion volume of $430 \mathrm{~mL} / \mathrm{g}$. Insufficiency $\mathrm{H}_{2} \mathrm{SO}_{4}$ would cause a incomplete intercalation reaction and leading to the decrease of dilatability; superfluous $\mathrm{H}_{2} \mathrm{SO}_{4}$ would cause the relative scarcity of $\mathrm{KMnO}_{4}$ and incomplete oxygenation of graphite.

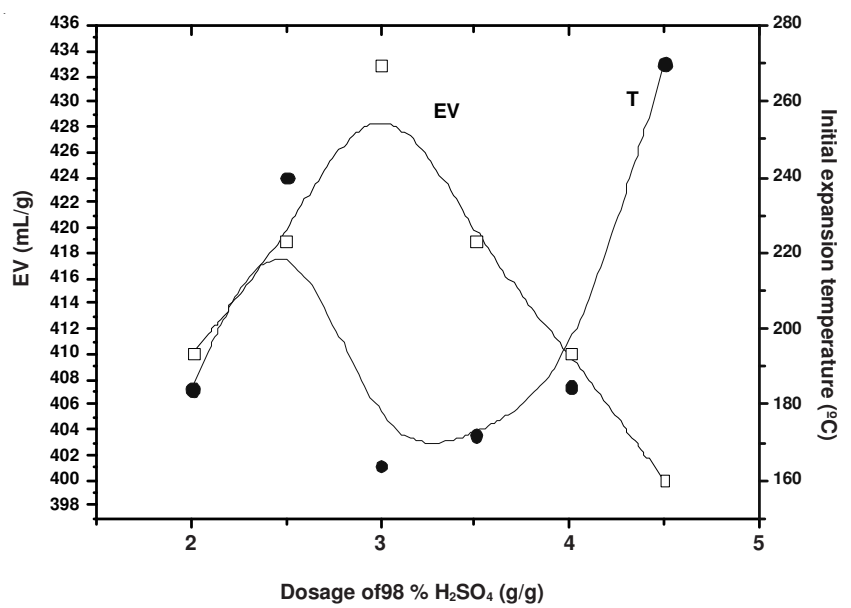

Fig. 2. Influence of $\mathrm{H}_{2} \mathrm{SO}_{4}$ dosage on initiation expansion temperature and expansion volume

Influence of $\mathrm{H}_{2} \mathrm{SO}_{4}$ concentration on expandable graphite expansion performance: By fixing the mass ratio C: $\mathrm{KMnO}_{4}: \mathrm{H}_{2} \mathrm{SO}_{4}(98 \%): \mathrm{H}_{3} \mathrm{PO}_{4}(85 \%)$ of 1.0:0.2:3.0:0.3 (g/g) and reacting for $1 \mathrm{~h}$ at $40{ }^{\circ} \mathrm{C}$, influence of $\mathrm{H}_{2} \mathrm{SO}_{4}$ mass concentration is detected. Before reaction, it is diluted with deionized water to the desired concentration. Results showed in Fig. 3 illustrate when $\mathrm{H}_{2} \mathrm{SO}_{4}$ concentration is controlled as $75 \%$, we can get expandable graphite with lower initiation expansion temperature of $160{ }^{\circ} \mathrm{C}$ and the higher expansion volume of $430 \mathrm{~mL} / \mathrm{g}$. Too high $\mathrm{H}_{2} \mathrm{SO}_{4}$ concentration would cause an excessive oxygenation of graphite, decrease of expansion volume and increase of initiation expansion temperature. Feasible mass concentration of $\mathrm{H}_{2} \mathrm{SO}_{4}$ can be set as $75 \%$.

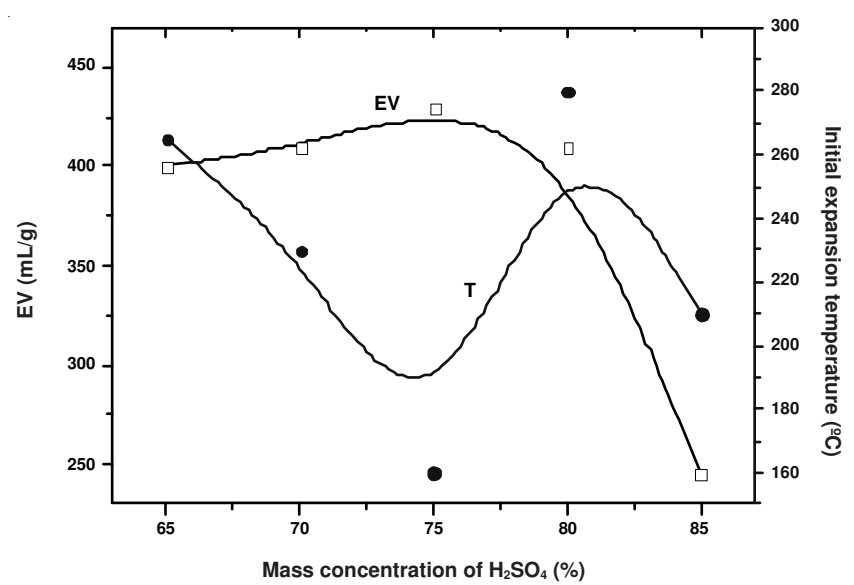

Fig. 3. Influence of $\mathrm{H}_{2} \mathrm{SO}_{4}$ mass concentration on initiation expansion temperature and expansion volume
Influence of $\mathrm{H}_{3} \mathrm{PO}_{4}$ dosage on expandable graphite expansion performance: In the range of $0.2-0.7 \mathrm{~g} / \mathrm{g}$, the influence of $\mathrm{H}_{3} \mathrm{PO}_{4}$ dosage is detected at the mass ratio $\mathrm{C}$ : $\mathrm{KMnO}_{4}: \mathrm{H}_{2} \mathrm{SO}_{4}(98 \%)$ of 1.0:0.2:3.0 (g/g) at $40{ }^{\circ} \mathrm{C}$ reacting for $1 \mathrm{~h}$ and $\mathrm{H}_{2} \mathrm{SO}_{4}$ is diluted to the mass concentration of $75 \%$ before reaction. As an ancillary intercalation reagent, increase of $\mathrm{H}_{3} \mathrm{PO}_{4}$ dosage can improve expandable graphite dilatability and reduce initiation expansion temperature (Fig. 4). When the mass ratio of $\mathrm{H}_{3} \mathrm{PO}_{4}$ to $\mathrm{C}$ is controlled as 0.3:1.0, we can get expandable graphite with initiation expansion temperature of $160{ }^{\circ} \mathrm{C}$ and expansion volume of $430 \mathrm{~mL} / \mathrm{g}$. Superfluous $\mathrm{H}_{3} \mathrm{PO}_{4}$ would cause the relative scarcity of $\mathrm{KMnO}_{4}$ and incomplete oxygenation of graphite.

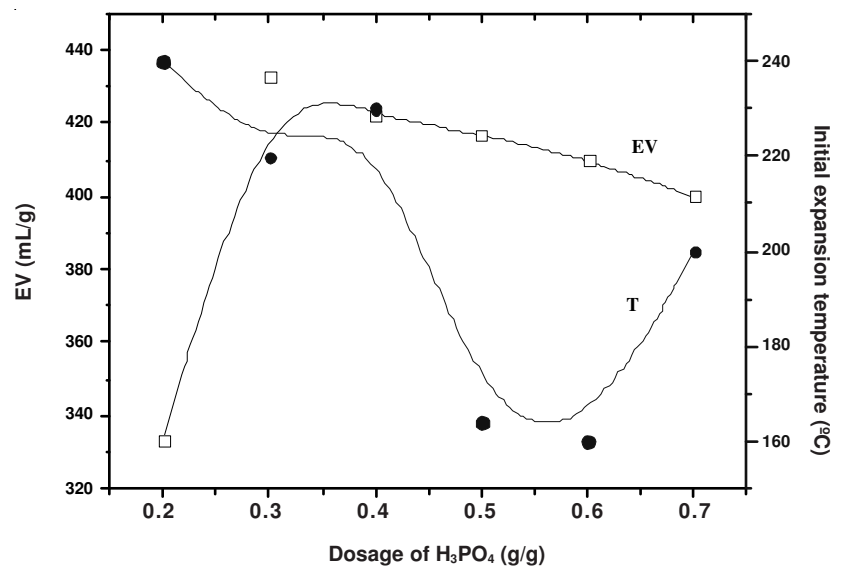

Fig. 4. Influence of $\mathrm{H}_{3} \mathrm{PO}_{4}$ dosage on initiation expansion temperature and expansion volume

Influence of reaction temperature on expandable graphite expansion performance: By fixing the mass ratio C: $\mathrm{KMnO}_{4}: \mathrm{H}_{2} \mathrm{SO}_{4}(98 \%): \mathrm{H}_{3} \mathrm{PO}_{4}(85 \%)$ of 1.0:0.2:3.0:0.3 (g/ g), $\mathrm{H}_{2} \mathrm{SO}_{4}$ is diluted to $75 \%$ and reacting $1 \mathrm{~h}$, influence of reaction temperature on initiation expansion temperature and expansion volume is detected. When it is less than $40^{\circ} \mathrm{C}$, the increase of temperature can improve expandable graphite dilatability (Fig. 5). While, too high temperature can lead to tempestuously exothermic reaction and excessive oxygenation of graphite. When reaction keeps at $40^{\circ} \mathrm{C}$, we can get expandable graphite with initiation expansion temperature of $160{ }^{\circ} \mathrm{C}$ and expansion volume of $430 \mathrm{~mL} / \mathrm{g}$.

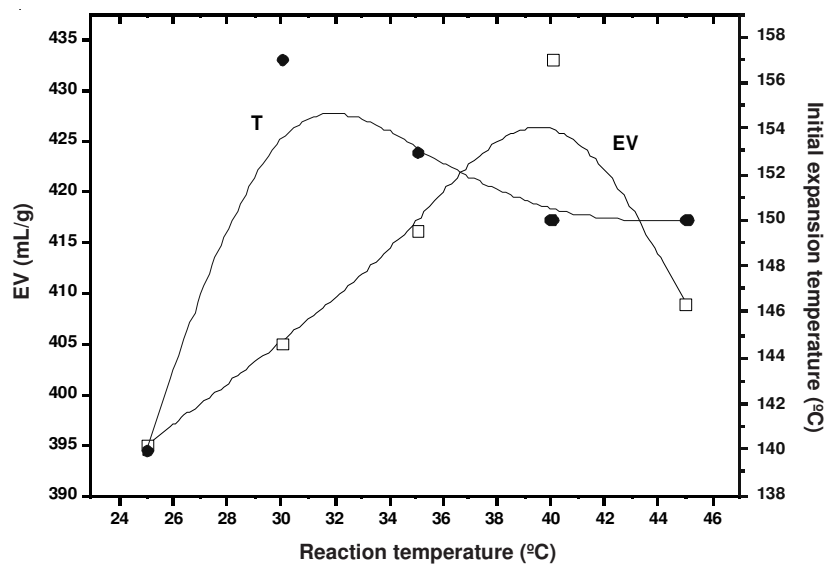

Fig. 5. Influence of reaction temperature on initiation expansion temperature and expansion volume 
Feasible condition to prepare expandable graphite: According to the experimental results, feasible conditions to prepare expandable graphite are: mass ratio C: $\mathrm{KMnO}_{4}: \mathrm{H}_{2} \mathrm{SO}_{4}$ $(98 \%): \mathrm{H}_{3} \mathrm{PO}_{4}(85 \%)$ equals to 1.0:0.2:3.0:0.3 $\left(\mathrm{H}_{2} \mathrm{SO}_{4}\right.$ diluted to mass concentration of $75 \%$ before intercalation reaction), reacts $1 \mathrm{~h}$ at $40{ }^{\circ} \mathrm{C}$. Initiation expansion temperature and expansion volume of the prepared expandable graphite are $160{ }^{\circ} \mathrm{C}$ and $430 \mathrm{~mL} / \mathrm{g}$, respectively. Expansion curve of the prepared expandable graphite is detected as Fig. 6. Expansion volume can reach $250 \mathrm{~mL} / \mathrm{g}$ at $400{ }^{\circ} \mathrm{C}$ and the maximum expansion volume of $430 \mathrm{~mL} / \mathrm{g}$ get at $800^{\circ} \mathrm{C}$.

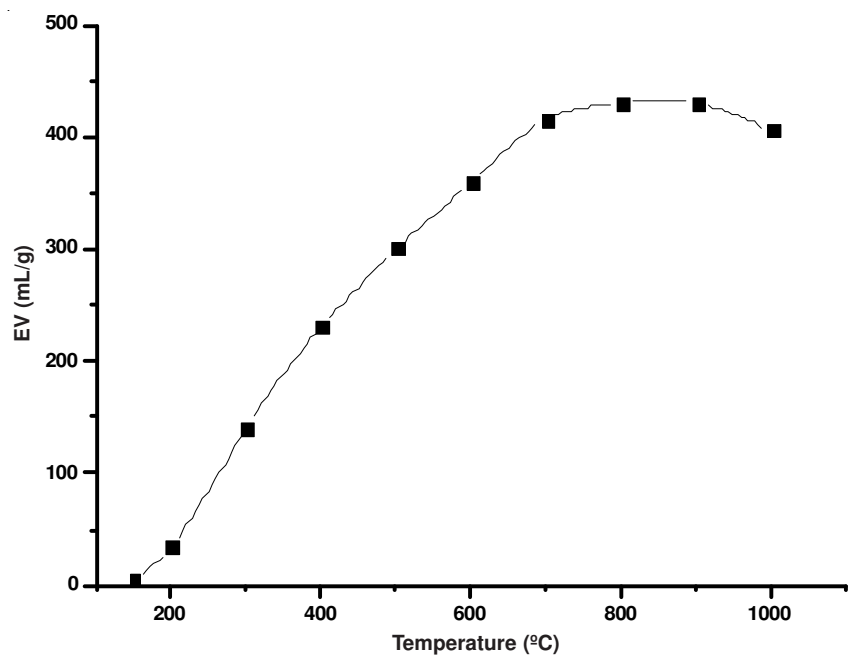

Fig. 6. Expansion curve of expandable graphite

Preparation of contrast expandable graphite with no assistant inserting reagent $\mathrm{H}_{3} \mathrm{PO}_{4}$ : Contrast expandable graphite is prepared under the condition of $\mathrm{C}: \mathrm{KMnO}_{4}: \mathrm{H}_{2} \mathrm{SO}_{4}$ $(98 \%)=1.0: 0.2: 3.0$ for $1 \mathrm{~h}$ at $40{ }^{\circ} \mathrm{C}$ and $\mathrm{H}_{2} \mathrm{SO}_{4}$ diluted to mass concentration of $75 \%$, no $\mathrm{H}_{3} \mathrm{PO}_{4}$ is added during reaction. Expansion volume and initial expansion temperature of contrast expandable graphite are detected as $350 \mathrm{~mL} / \mathrm{g}$ and $170{ }^{\circ} \mathrm{C}$.

XRD analysis of expandable graphite: XRD analysis results for material graphite and the expandable graphite are showed in Fig. 7. Diffraction peaks of 3.34 and $1.67 \AA$ are the two characteristic spectrums of natural graphite. Because it has graphene planes, the peak of $3.34 \AA$ is strengthened during XRD detection. In the XRD analysis of the prepared expandable graphite, the characteristic peak of $3.34 \AA$ is replaced with $3.40 \AA$. The results show the layer space is bigger than the natural graphite and new substance has inserted into graphene planes. Compared with standard spectrums, the possible form of $\mathrm{H}_{3} \mathrm{PO}_{4}$ in graphene planes might be $\mathrm{H}_{3} \mathrm{PO}_{4} \cdot 0.5 \mathrm{H}_{2} \mathrm{O}, \mathrm{H}_{4} \mathrm{P}_{2} \mathrm{O}_{7}, \mathrm{HPO}_{3}$ or $\mathrm{P}_{2} \mathrm{O}_{5}$ and they are typical phosphorus flame retardant. We can deduce the prepared expandable graphite possesses well flame retardancy than the contrast expandable graphite.

Antiflame capability of expandable graphite for LLDPE: LLDPE is a flammable material and with a low processing temperature $c a .140^{\circ} \mathrm{C}$. So we can select the prepared expandable graphite as flame retardant. Flame retardants are added to LLDPE according to the proportion listed in Table-1. After mixing, pressing into piece and cutting into strip, the LOC is

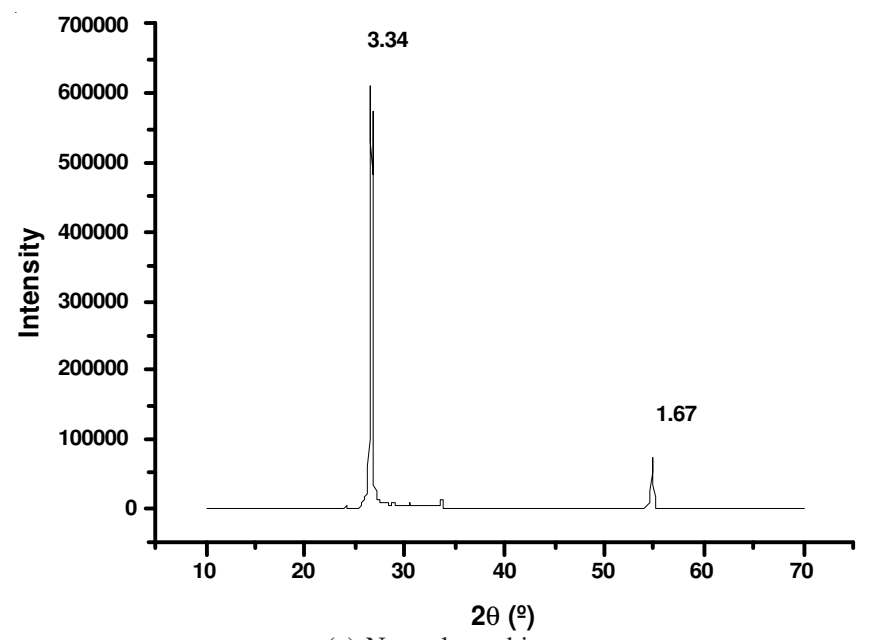

(a) Natural graphite

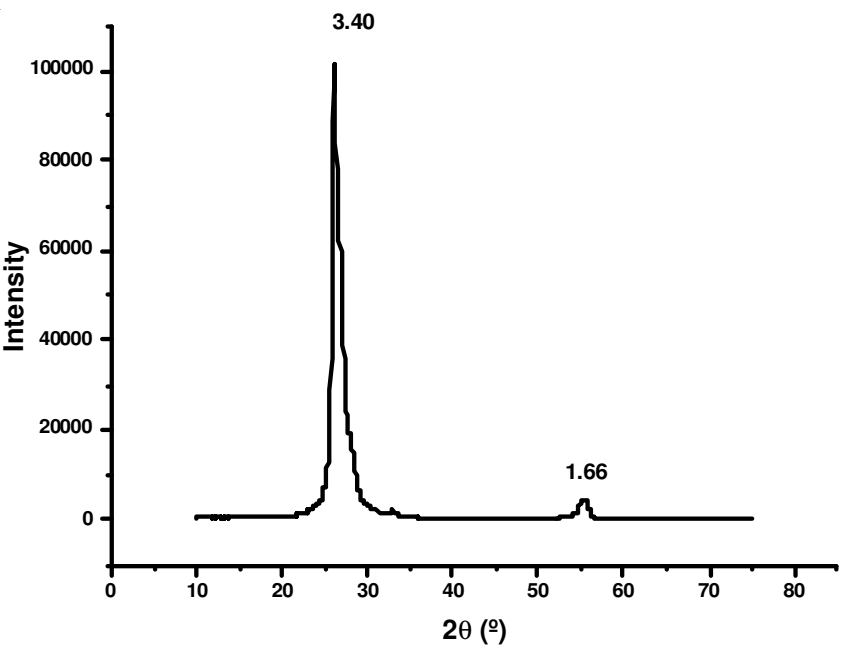

(b) expandable graphite

Fig. 7. XRD of natural graphite and the prepared expandable graphite

detected and the results are listed in Table-1. Addition of $30 \%$ expandable graphite can improve LOC up to $25.7 \%$. But the addition of the same amount of the contrast expandable graphite or purchase expandable graphite to LLDPE can only get a LOC of 24.4 and $23 \%{ }^{20}$, respectively. So the addition of assistant inserting reagent $\mathrm{H}_{3} \mathrm{PO}_{4}$ can improve expandable graphite dilatability and flame retardancy. LOC is only 19.3 $\%$ with single $30 \%$ APP(II) as flame retardant and the addition of $20 \%$ expandable graphite together with $10 \%$ APP(II) can improve LOC to $27.0 \%$, it show the synergistic antiflame of expandable graphite with APP(II).

\begin{tabular}{cccccc}
\multicolumn{7}{c}{ TABLE-1 } \\
\multicolumn{7}{c}{ RESULTS OF LOI } \\
\hline \multirow{2}{*}{ Samples } & $\begin{array}{c}\text { LLDPE } \\
(\%)\end{array}$ & $\begin{array}{c}\text { EG } \\
(\%)\end{array}$ & Contrast & APP(II) & LOI \\
& $1 \%)$ & $(\%)$ & $(\%)$ \\
\hline 1 & 100 & 0 & 0 & 0 & 17.3 \\
2 & 70 & 0 & 0 & 30 & 19.3 \\
3 & 70 & 10 & 0 & 20 & 24.2 \\
4 & 70 & 20 & 0 & 10 & 27.0 \\
5 & 70 & 30 & 0 & 0 & 25.7 \\
6 & 70 & 0 & 30 & 0 & 24.4 \\
\hline
\end{tabular}

Thermal analysis: TG analysis results for samples of $70 \%$ LLDPE/10 \% APP(II)/20 \% expandable graphite and $70 \%$ 
LLDPE/30 \% expandable graphite are showed as Fig. 8a. Mass loss in the first stage among $100-400{ }^{\circ} \mathrm{C}$ is less than $5.0 \%$, which are caused by decomposition of APP(II) and initial expansion of expandable graphite. Mass loss in the second stage among $400-500{ }^{\circ} \mathrm{C}$ are nearly $74 \%$ and $67 \%$ for $70 \%$ LLDPE/ $30 \%$ expandable graphite, $70 \%$ LLDPE/10 \% APP(II)/20\% expandable graphite, respectively. Mass loss occurred in the second stage is caused by expansion of expandable graphite, for expandable graphite has represented well expansion capacity among $400-500{ }^{\circ} \mathrm{C}$ (Fig. 6). Compare sample 4 to sample 5 , the synergistic antiflame of expandable graphite with APP (II) gives higher residual carbon of $27.0 \%$ than $70 \%$ LLDPE/ $30 \%$ expandable graphite of $18.44 \%$, then cause a higher retardancy LOI and better antiflame capability for LLDPE.

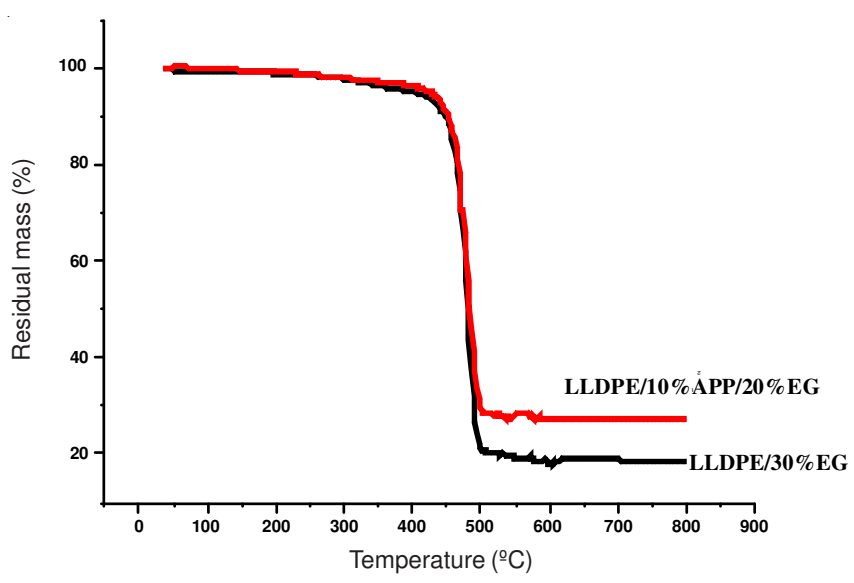

(a) TG

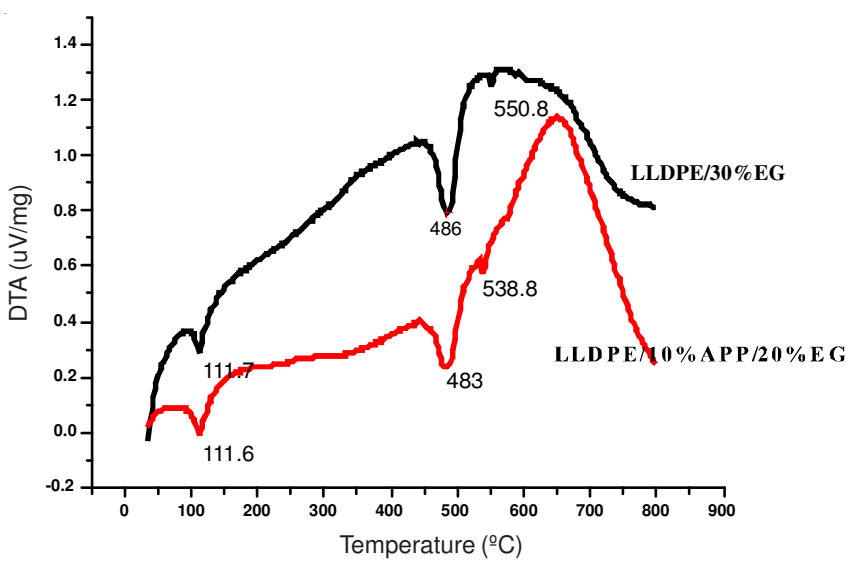

(b) DTA

Fig. 8. TG and DTA analysis of $70 \%$ LLDPE/10 \% APP/20 \% expandable graphite and $70 \%$ LLDPE/30 \% expandable graphite

During decomposition of APP(II) and expansion of expandable graphite, they will consume huge heat and then reduce material temperature. As showed in Fig. 8b, peaks corresponding to $111^{\circ} \mathrm{C}$ are melting decalescence of LLDPE. 483 and $486{ }^{\circ} \mathrm{C}$ are two strong decalescence peaks corresponding to expandable graphite expansion in $70 \%$ LLDPE/10\% APP/20 \% expandable graphite sample and $70 \%$ LLDPE/30 \% expandable graphite sample, respectively. $70 \%$ LLDPE/10 \% APP(I)/20 \% expandable graphite sample shows stronger decalescence and give lower surface temperature than $70 \%$ LLDPE/30 \% expandable graphite sample.
Analysis of antiflame mechanism: When expandable graphite exposes to flame, it gives a swollen multicellular char, which limits heat and mass transfer, as well as oxygen diffusion. Instantaneous expansion of expandable graphite can absorbs huge heat and releases $\mathrm{CO}_{2}, \mathrm{H}_{2} \mathrm{O}$ and $\mathrm{SO}_{2}$, which can reduce oxygen concentration; Coexistence of expandable graphite and APP(II) can give more residual carbon and induce lower surface temperature, that cause well synergistic flame retardancy.

\section{Conclusion}

Adjustment of $\mathrm{KMnO}_{4}, \mathrm{H}_{2} \mathrm{SO}_{4}$ and $\mathrm{H}_{3} \mathrm{PO}_{4}$ dosages can influence expandable graphite expansion performance. The feasible condition to get expandable graphite with low initiation expansion temperature and high expansion volume is: $\mathrm{C}$ : $\mathrm{KMnO}_{4}: \mathrm{H}_{2} \mathrm{SO}_{4}(98 \%): \mathrm{H}_{3} \mathrm{PO}_{4}(85 \%)=1.0: 0.2: 3.0: 0.3$ (mass ratio), the reaction lasts $1.0 \mathrm{~h}$ at $40{ }^{\circ} \mathrm{C}$ and $\mathrm{H}_{2} \mathrm{SO}_{4}$ need to be diluted to a mass concentration of $75 \%$. Under this condition, expandable graphite with an initiation expansion temperature of $160{ }^{\circ} \mathrm{C}$ and expansion volume of $430 \mathrm{~mL} / \mathrm{g}$ can be gained. Expandable graphite possess well antiflame capability for its absorbing huge heat, releasing noncombustible gas, giving birth to multicellular, adiabatic and insulating oxygen char, which acts as physical barrier for heat and mass transfer. There is synergistic flame retardancy between expandable graphite and APP(II) for they can cause higher residual carbon than the expandable graphite single antiflame system.

\section{ACKNOWLEDGEMENTS}

This study was supported Doctor Foundation of Hebei province Education Office (China, No. B2004402).

\section{REFERENCES}

1. M. Alaee, P. Arias, A. Sjodin and A. Bergman, Environ. Int., 29, 683 (2003).

2. I. Watanabe and S.I. Sakai, Environ. Int., 29, 665 (2003).

3. J.Z. Su, A.K. Kim and M. Kanabus-Kaminska, Fire Safety J., 31, 1 (1998).

4. C.S. Chou, S.H. Lin and C.I. Wang, Adv. Powder Technol., 20, 169 (2009).

5. J.W. Gu, G.C. Zhang, S.L. Dong, Q.Y. Zhang and J. Kong, Surf. Coat. Technol., 201, 7835 (2007).

6. X.L. Chen, K.M. Song and J.H. Li, Chinese Carbon, 34, 1599 (1996).

7. X.Y. Pang and J.H. Liu, Asian J. Chem., 22, 3014 (2010).

8. W.B. Gan and X.B. Zeng, J. Wuhan Univ. Technol., 14, 55 (1992).

9. F.Y. Kang, Y.P. Zheng, H.N. Wang, Y. Nishi and M. Inagaki, Carbon, 40, 1575 (2002).

10. H. Zhao, W. Zhou, W.C. Shen and F.Y. Kang, Chin. Mater. Sci. Eng., 20, 153 (2002).

11. H.F. Zhu, Q.L. Zhu, J. Li, K. Tao, L.X. Xue and Q. Yan, Polym. Degrad. Stab., 96, 183 (2011).

12. S. Duquesne, M.L. Bras, S. Bourbigot, R. Delobel, H. Vezin, G. Camino, B. Eling, C. Lindsay and T. Roels, Fire Mater., 27, 103 (2003).

13. K.M. Song and L. Wang, CN Patent 200610012936.1 (2006).

14. L. Wang, K.M. Song, S.H. Zhang, Q. Li, Y.P. Li and M. Liu, Bull. Chin. Ceram. Soc., 28, 844 (2009).

15. X.Y. Pang, S.K. Zhi, Y.J. Su, L. Liu and F. Lin, J. Hebei Univ. (Nat. Sci.), 31, 497 (2011).

16. S. Horold, Polym. Degrad. Stab., 64, 427 (1999).

17. P.L. Kuo, J.M. Chang and T.L. Wang, J. Appl. Polym. Sci., 69, 1635 (1998).

18. L.L. Wei, D.Y. Wang, H.B. Chen, L. Chen, X.L. Wang and Y.Z. Wang, Polym. Degrad. Stab., 96, 1557 (2011).

19. G.Q. Xi, X.Y. Pang, J.S. Wang and Y.J. Su, Chin. Non-Miner., 34, 18 (2011).

20. A.H. Yan, Z.Q. Zhou and Z. Wu, Chin. Chem. Eng., 3, 48 (2006). 